\title{
22 Cyclostomes (Lamprey and Hagfish)
}

\author{
Fumiaki Sugahara
}

\section{CONTENTS}

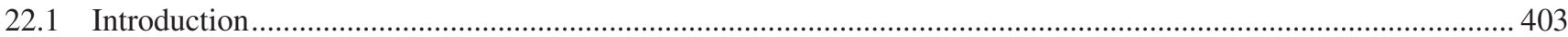

22.1.1 Cyclostomes for Evolutionary Research of Vertebrates.......................................................................... 403

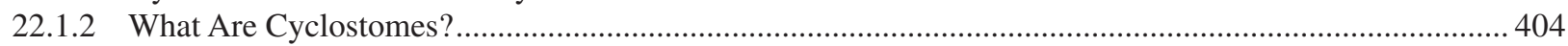

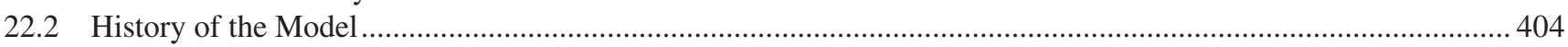

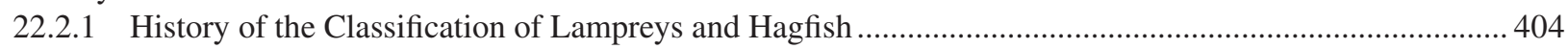

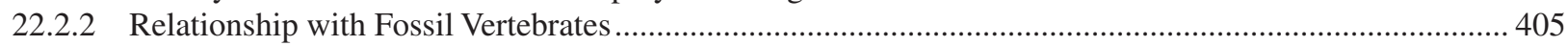

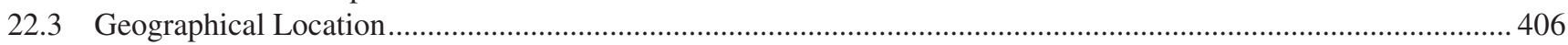

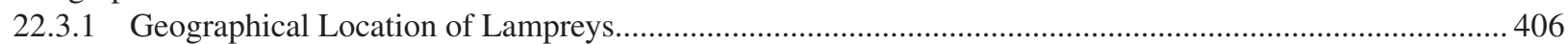

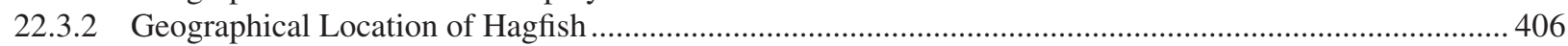

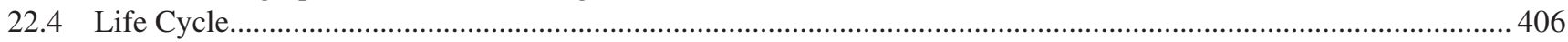

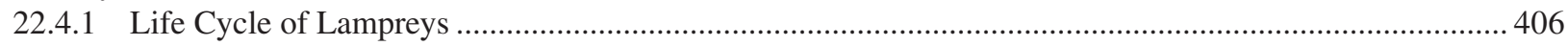

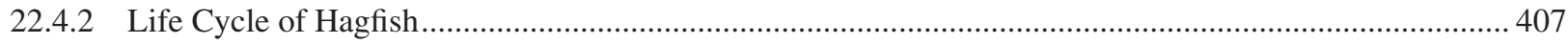

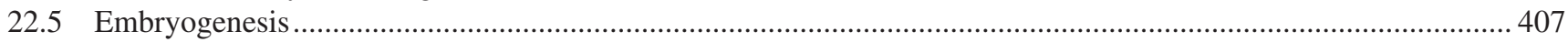

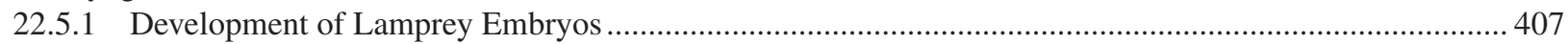

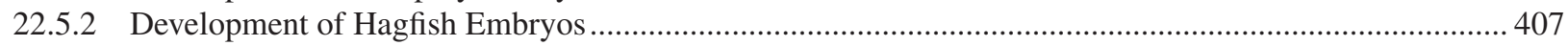

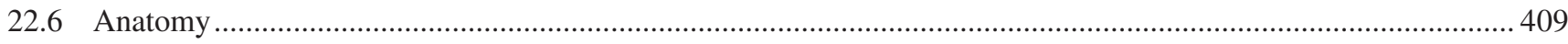

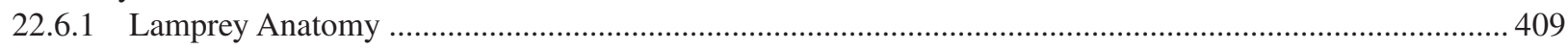

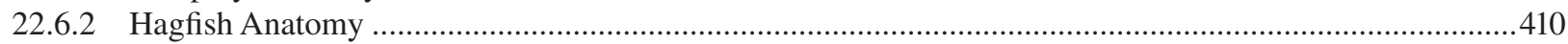

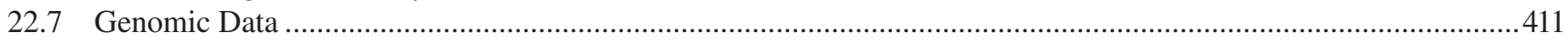

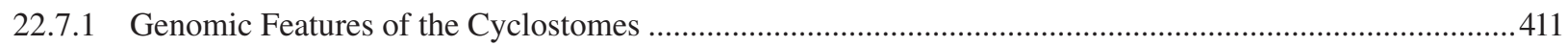

22.7.2 Chromosome Elimination and Programmed Sequence Loss in Cyclostomes ...........................................412

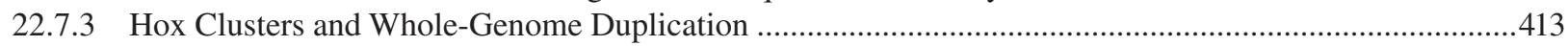

22.8 Functional Approaches: Tools for Molecular and Cellular Analyses.....................................................................413

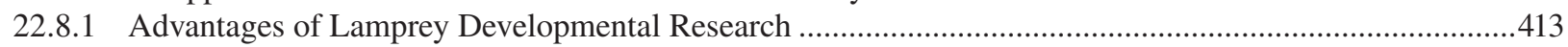

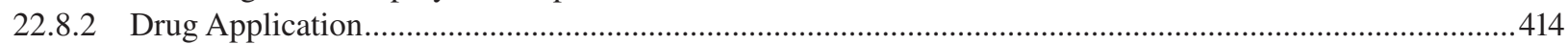

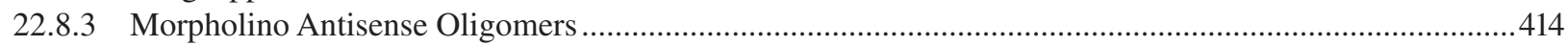

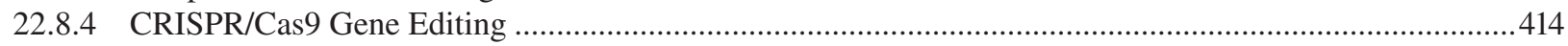

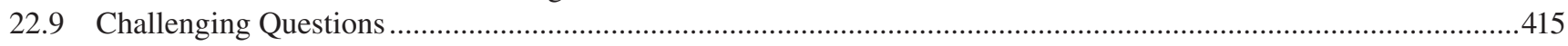

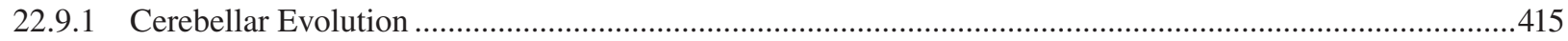

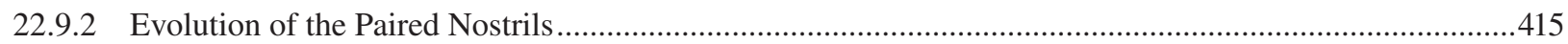

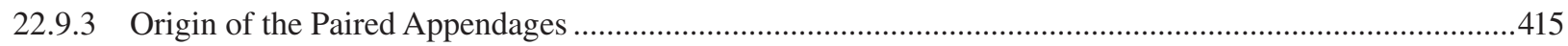

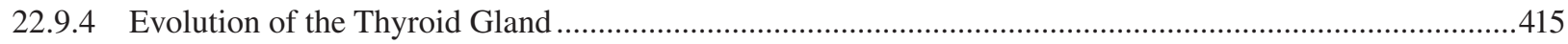

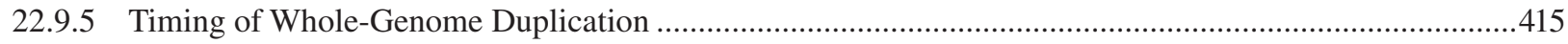

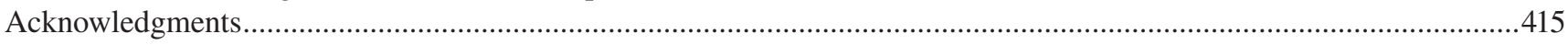

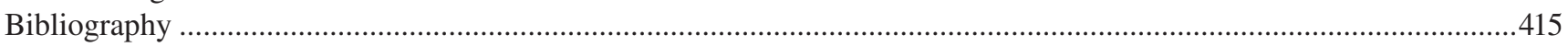

\subsection{INTRODUCTION}

\subsubsection{Cyclostomes for Evolutionary Research of Vertebrates}

Living jawless fish diverged from a common vertebrate ancestor over 500 million years ago (mya). They comprise two groups, lampreys and hagfish, which form the monophyletic group Cyclostomata based on molecular phylogenetic analyses. Cyclostomes are important model organisms for understanding early vertebrate evolution because they retain many features that ancient jawless vertebrates had. However, it should be noted that since they are not "ancestral animals", cyclostomes lived independently from the jawed vertebrate (or gnathostome) lineages following divergence and thus possess independently evolved traits. Therefore, careful comparison of each trait among lampreys, hagfish and jawed vertebrates would allow us to determine which traits are primitive and which are derived and thus depict the ancestry of early vertebrates. Until recently, lampreys have been used as model organisms of jawless vertebrates, especially in developmental biology. Recently, however, it has become possible to obtain fertilized eggs from inshore 
hagfish species and study their developmental mechanisms. In this chapter, the characteristics of both lampreys and hagfish are described as model organisms for the evolution of vertebrates, and challenging questions are suggested from genomic and developmental perspectives.

\subsubsection{What Are Cyclostomes?}

Cyclostomes comprise the extant lampreys and hagfish (Figure 22.1) as well as various extinct species. There are 38 extant lamprey species, of which 9 live in freshwater throughout their lifecycle, and 18 species feed parasitically as adults (Nelson et al. 2016). Adult lampreys have a sucker-shaped mouth with horny teeth instead of an articulated jaw with enameled teeth like gnathostomes (Figure 22.1b). Seven pairs of gill pores open behind the eyes. A single median nostril, called the nasohypophyseal duct, opens on the dorsal side of the head and ends in a blind sac. Lampreys do not have paired pectoral and pelvic fins, both of which are homologs of tetrapod limbs. All living lampreys have a larval stage called ammocoetes. During this stage, the eyes are undeveloped under the skin, and the mouth is not rounded but divided into upper and lower lips (Figure 22.1c). Ammocoetes larvae live at the bottom of rivers as filter feeders. After metamorphosis, some species live as parasites that feed by boring into the flesh of other fish to suck their blood, while others do not feed throughout the adult stage. Most parasitic species migrate from rivers to the sea after metamorphosis and return to the upstream of the river during the breeding season.

There are 29 extant hagfish species (Figure 22.1d). The vertebrae are almost absent. Similar to lampreys, a single nasohypophyseal duct opens at the rostral end of the head, but the internal duct does not end in a blind sac as it does in lampreys but rather opens into the pharynx. The eyes lack lenses, all extraocular muscles and nerve innervation (cranial nerves III, IV and VI). The 1-16 external gill openings are located relatively ventral and caudal compared with those of lampreys. The lateral line system is highly degenerate, and they have no paired fins. Hagfish are widely regarded as scavenger feeders and mostly eat dead animals using a tongue apparatus with a horny dental apparatus. When they encounter predators, they release mucous from 70 to 200 pores in the ventrolateral body that forms slime when coming into contact with seawater. Most hagfish species live in deep-sea habitats, but some species belonging to the genus Eptatretus live relatively inshore. For example, the Japanese inshore hagfish Eptatretus burgeri lives at depths of 10-270 m (Jørgensen et al. 2012). In contrast to lampreys, all hagfish species undergo direct development without the larval stage.

\subsection{HISTORY OF THE MODEL}

\subsubsection{History of the Classification OF LAMPReYS AND Hagfish}

Cyclostomes are important model organisms because they are the only extant jawless vertebrates, a characteristic that is shared with fossil Silurian and Devonian fish. Thus, they are in a unique phylogenetic position (Figure 22.2). However, the phylogenetic relationship between lampreys and hagfish has been the subject of controversy until recently. Carl Linneaus, the father of modern taxonomy, originally classified hagfish as Vermes intestina, since they lack vertebrae, which is the most important synapomorphy of vertebrates (Linnaeus 1758). In addition, the ammocoetes were initially thought to be a separate species from adult lampreys but were later revealed to be larval lampreys (Müller 1856). It was proposed that lampreys and hagfish be grouped together into "Cyclostome" based on their shared traits of a single nostril and lack of paired fins (Duméril 1806). However, Løvtrup (1977) stated that lampreys are more closely related to jawed vertebrates. Janvier (1996) supported Løvtrup's statement and proposed that hagfish should be placed as a sister group of the other vertebrates called "Craniata" and that lampreys and gnathostomes

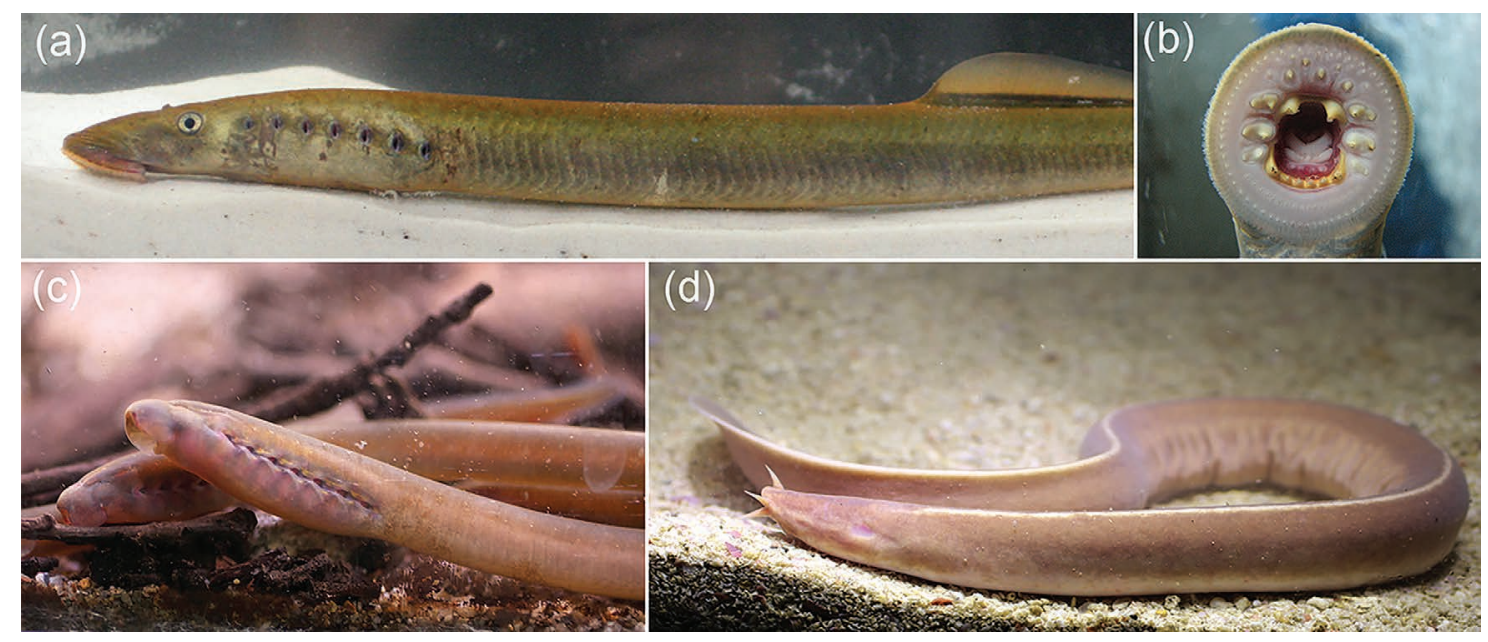

FIGURE 22.1 Lamprey and hagfish. (a-c) Arctic lamprey Lethenteron camtschaticum. (b) Oral funnel and horny teeth of adult lamprey. (c) Ammocoetes larvae of lamprey. Note that eyes are undeveloped under the skin, and upper and lower lips cover the mouth instead of the oral funnel. (d) Japanese inshore hagfish Eptatretus burgeri. 


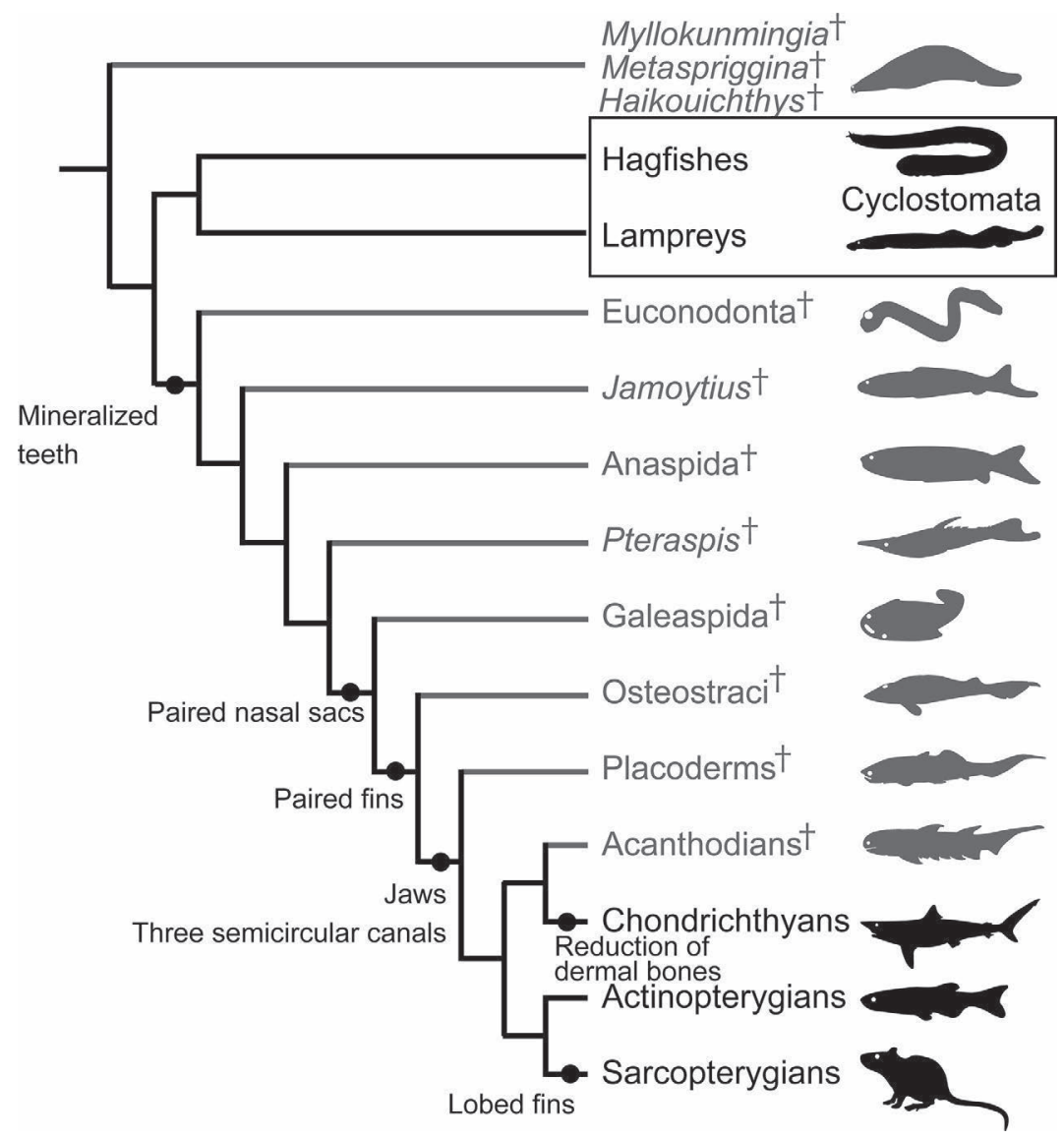

FIGURE 22.2 Phylogeny of the major vertebrate lineages including fossil fish. This tree is based on Morris and Caron (2014) for fossil jawless vertebrates and Zhu et al. (2013) for jawed vertebrates. Gray lines indicate extinct fossil lineages. Round spots indicate major changes toward crown gnathostomes. (From Janvier 1996; Gai et al. 2011).

be classified as "Vertebrata". This classification was widely accepted by paleontologists and morphologists until recently.

However, since the emergence of molecular phylogenetic analysis in the 1990s, lampreys and hagfish have been grouped as a monophyletic group (Kuraku et al. 1999; Mallatt and Sullivan 1998). This monophyletic theory has been repeatedly supported by the presence of cyclostome-specific miRNA (Heimberg et al. 2010), as well as the shared development of the head in lampreys and hagfish (Oisi et al. 2013). Thus, cyclostome monophyly has been widely supported (Figure 22.2).

\subsubsection{Relationship with Fossil Vertebrates}

The earliest vertebrates did not have an articulated jaw and are therefore called "Agnathan". Cambrian Myllokunmingia, Metaspriggina and Haikouichthys are thought to be early jawless vertebrates (Figure 22.2). Although the ancestors of cyclostomes might have diverged more than 500 million years ago, based on molecular phylogenetic studies (Kuraku and Kuratani 2006), no fossils have been found that can be identified as cyclostomes from this geological period. Later, the ancestor of cyclostomes split into two groups, the lampreys and hagfish, between 430 and 480 million years ago. The earliest lamprey fossil appears to be Priscomyzon riniensis, which lived during the Late Devonian (Gess et al. 2006). In addition, fossils of lamprey larvae have been found in the Lower Cretaceous, suggesting that the threephased (larva-metamorphosis-adult) life cycle of the lamprey was established at least during this period (Chang et al. 2014). Conversely, hagfish fossils are rare, but Myxinikela siroka from the Carboniferous is a definite hagfish fossil (Bardack 1991). More ancient fossil fish have been found in the Devonian, and Palaeospondylus gunni is classified as a primitive hagfish (Hirasawa et al. 2016), but contrasting opinions have also been proposed based on the presence of three semicircular canals (Johanson et al. 2017).

After the divergence of cyclostomes, Conodonts, Jamoytius, Anaspida and Pteraspis are thought to have diverged (Figure 22.2). A Silurian osteocoderm (shell-skinned fish) group, Galeaspis, still did not have jaws but had two separated nasal sacs and a hypophyseal duct opening into the oral cavity as in gnathostomes. Therefore, they show intermediate head morphology between jawless and jawed vertebrates (Gai et al. 2011). Placoderms appear to have been the first group to acquire jaws (Figure 22.2), even though the head and brain morphology of primitive placoderms was similar to that of jawless vertebrates and cyclostomes (Dupret et al. 2014). 


\subsection{GEOGRAPHICAL LOCATION}

\subsubsection{Geographical Location of Lampreys}

Most lamprey species live in the cool zone of the northern hemisphere, generally north of $30^{\circ} \mathrm{N}$. The most cosmopolitan lamprey is the sea lamprey Petromyzon marinus, which is thus the species most commonly used as a model organism in North America and Europe. They live in the Great Lakes, the Atlantic and Pacific oceans and the Mediterranean Sea along the shores of Canada, the United States, Iceland, and Europe. They are mostly anadromous (seagoing), but the Great Lakes population is landlocked. This species is one of the largest lamprey species and can reach $1.2 \mathrm{~m}$ in length and $2.3 \mathrm{~kg}$. The arctic lamprey Lethenteron camtschaticum is another important model organism for evolutionary developmental biology in the Far East. They are distributed throughout the Arctic extending south to Japan and Korea. Most of them are anadromous, but landlocked habitats have been observed in some areas (Yamazaki et al. 2011). The European river lamprey Lampetra fluviatilis (anadromous) and brook lamprey Lampetra planeri (freshwater) have been studied by European researchers. In the southern hemisphere, the pouched lamprey Geotria australis and the southern topeyed lamprey Mordacia are distributed in Australia (including Tasmania), New Zealand, Chile, Argentina, the Falkland Islands and South Georgia Island. Even though they are thought to have diverged from the northern lamprey 220-280 mya, there are fewer apparent morphological differences between them.

\subsubsection{Geographical location of Hagfish}

Hagfish occur in all oceans except for the polar seas. All species prefer cool water $\left(<15^{\circ} \mathrm{C}\right)$ and therefore live in deep water or locations where the water is cool. Extant hagfish can be divided into two major genera, Myxine and Eptatretus. The major morphological difference between them is the number of external gill apertures. That is, Myxine is defined as having one pair of common gill openings, whereas Eptatretus is characterized as having one duct as an exit from each gill pouch. The Atlantic hagfish Myxine glutinosa was first described by Linnaeus (1758) and is commonly found around the Atlantic Ocean in Europe and North America. Among the Myxine species, M. glutinosa lives in exceptionally shallow water $(<40 \mathrm{~m})$, but most Myxine species live in deep water where light does not reach. A relatively large number of studies have been reported on the behavior and embryonic development of Eptatretus, since they generally live in shallower seas than Myxine. The Pacific hagfish Eptatretus stoutii is distributed in the eastern north Pacific from Canada and the United States to Mexico in water of 16-633 m depth (Jørgensen et al. 2012). At the end of the 19th century, Bashford Dean collected fertilized eggs of $E$. stoutii (synonym: Bdellostoma stoutii) from Monterey Bay, California, and first described their embryonic development (Dean 1899). E. burgeri is distributed around Japan, Korea and Taiwan and has been used in developmental studies recently (Ota et al. 2007). As in lampreys, there are only a few genera in the southern hemisphere, such as Notomyxine, Neomyxine and Nemamyxine. It has been noted that these genera might have diverged early from the northern hagfishes based on 16S rDNA data (Fernholm et al. 2013). Further phylogenetic studies are needed to elucidate the phylogeny of extant hagfish.

\subsection{LIFE CYCLE}

\subsubsection{Life Cycle of Lampreys}

The life cycle of lampreys is highly complex, because they undergo three major morphological and physiological stages, ammocoetes larva, metamorphosis and adult. Mature adults spawn in nests of sand in the upper streams of rivers. Fertilized eggs hatch within two weeks and develop into ammocoetes larvae within about one month (see Section 22.5 for details). Ammocoetes larvae have undeveloped eyes under the skin, and their mouth is not rounded but divided into upper and lower lips (Figure 22.1c). They live as filter feeders, buried in mud, sand and organic detritus along rivers. The mucus secreted by the endostyle is used for this feeding behavior, as in amphioxi or ascidians. According to a study using stable isotope ratios $\left(\delta^{13} \mathrm{C}\right.$ and $\left.\delta^{15} \mathrm{~N}\right)$ in $P$. marinus larvae, they are primarily consumers of aquatic sediments, including macrophytes, algae and terrestrial plants (Evans and Bauer 2016). In an aquarium environment, dry yeast or the unicellular alga Chlorogonium capillatum (NIES-3374) can be used as a food source (Tetlock et al. 2012; Higuchi et al. 2019). The larval stage lasts for a number of years (e.g. L. camtschaticum: 2-5 years). The trigger for the transition to metamorphosis is probably not the length of the larval period but rather the larval size. Once larvae reach a certain length (e.g. L. camtschaticum: $\sim 16 \mathrm{~cm}$ [Kataoka 1985]), they proceed to the metamorphic stage. Metamorphosis lasts for approximately one month. During this period, the oral apparatus changes into a round, sucker-like disc lined with horny teeth. The medial dorsal fin is higher, and the eyes are fully functional.

The adult life of lampreys varies considerably between parasitic and non-parasitic species. Many parasitic species are anadromous, migrating downstream to the sea and sucking on fish to feed on their blood. However, these species are not only parasites but also scavenge dead animals or prey on fresh fish as predators. Non-parasitic species spend their whole lives in freshwater and are sexually mature for less than a year. Usually, parasitic and non-parasitic behaviors are species specific, but the two types of behavior are sometimes found in the same species (Yamazaki et al. 2011).

Before the breeding season, parasitic species begin to migrate upstream. As they approach sexual maturity, males develop a urogenital papilla, a penis-like funnel-shaped organ elongated from the cloaca (Figure 22.4e). The abdomen of the female is visibly enlarged, and a post-cloacal finfold develops (Figure 22.4f). Mating behavior occurs in their nests, which are constructed by thrashing their bodies and mouths 
to remove stones. A male attaches itself to the female's head and wraps his tail around her trunk to assist in the extrusion of eggs. Finally, the couple vibrates vigorously for a few seconds to release eggs and sperm so they can be externally fertilized. All individuals die within a few days after spawning.

\subsubsection{Life CyCle Of Hagfish}

In contrast to lampreys, the life cycle of hagfish might be relatively simple, because they undergo direct development with no larval and metamorphosis stages. However, many aspects of the hagfish life cycle remain unknown because they live in deep-sea habitats, and even their basic life history characteristics, such as growth rate, lifespan, sexual maturity and reproductive behavior, remain unclear. All of the described hagfish species prefer high salinity. For example, M. glutinosa dies rapidly in salinities of 20-25 ppt (Gustafson 1935). This could explain why hagfish do not occur in polar seas. Most species tend to live in deep waters. An unknown Eptatretus sp. was photographed at a depth of over 5,000 m (Sumich 1992). Although each species has a characteristic depth range, the range can be quite broad in some cases. For instance, $M$. glutinosa can be found at depths of $30 \mathrm{~m}$ in the northern Gulf of Maine, whereas this species has been collected at depths of 1,100 m in North America (Jørgensen et al. 2012).

E. burgeri is the only known species to show seasonal migration. On the Pacific side of mid-Japan, this species is found in quite shallow water (6-10 $\mathrm{m}$ depth) from mid-October to mid-July. Subsequently, these hagfish swim deeper than $50 \mathrm{~m}$ until September (Ichikawa et al. 2000). Although it is unknown whether this migration is related to water temperature or breeding behavior, researchers have failed to collect eggs by net sweeping at $40-110 \mathrm{~m}$ depth, suggesting that the spawning ground of this animal might be deeper than $100 \mathrm{~m}$. Other studies have reported that differences in habitat depend on size and sex. Most E. stoutii are found at $100 \mathrm{~m}$ depth, where the ratio of males to females is 1:1, whereas larger females are predominant at $500 \mathrm{~m}$ (Jørgensen et al. 2012). Many species prefer to hide in the sand or mud on the sea floor, whereas others prefer the shade of rocks. Generally, hagfish are thought to be scavengers, eating dead fish and whales. However, many studies have showed that they are predators who attack and eat invertebrates and vertebrates, such as polychaetes, shrimp and fish. In addition, they are opportunistic scavengers on dead animals.

The most unique feature of hagfish is their ability to release large amounts of slime consisting of mucous and fibrous components from glands. This function is mainly defensive against predators. When they are physically attacked by predators, hagfish rapidly eject slime, which entrains large volumes of water and traps predators' head and gills. See Fudge et al. (2016) for further details of hagfish slime.

Little is known about hagfish reproduction, including the maturation mechanism, mating behavior, fertilization or embryonic development. This is because the location and timing of hagfish spawning remain unknown. The eggs seem to be fertilized externally, because hagfish do not have mating organs. However, mating behavior also remains unknown.
Exceptionally, small numbers of fertilized eggs of the inshore hagfish E. burgeri have been collected every year since 2006 (Ota et al. 2007). In mid-August, pre-mature males and females can be caught at a depth of $100 \mathrm{~m}$ in the Sea of Japan. When they are kept on the bottom of the sea in cages, they lay eggs in late October (Oisi et al. 2015). Embryonic development is slow, with eggs taking approximately one year to hatch. Juveniles are almost identical to adults, except for carrying the yolk sac.

\subsection{EMBRYOGENESIS}

\subsubsection{Development of Lamprey Embryos}

Fertilized eggs of lampreys can be obtained by artificial fertilization during the breeding season once a year (Sugahara et al. 2015). L. camtschaticum eggs are approximately $1 \mathrm{~mm}$ in size, which is similar but slightly smaller than Xenopus eggs. Double-layered chorion surrounds the eggs. They are telolecithal eggs and show holoblastic cleavage. For staging, Tahara's developmental stages for L. reisnneri are widely used (Tahara 1988) (Figure 22.3a). At stage 13, gastrulation begins below the equator as in Xenopus. The blastopore is elliptical, while the yolk plug is not formed. At stage 17, the neural groove arises in the middle of the neural plate and changes to a neural fold. Both neural folds are almost parallel throughout the embryos, even in the head region, which is different from those in frogs and zebrafish. After neurulation, head protrusion is visible, and the cheek processes (mandibular arch and first pharyngeal pouch) appear on the lateral side of the protrusion. One of the unique features of lamprey embryos is that the nasal placode is single and fused with the hypophyseal placode at the anterior end to the mouth opening, forming a nasohypophyseal placode. Around stage 25 (approx. $10 \mathrm{dpf}$ ), eggs hatch and the heart starts beating. At stages 27 and 28, the eye spots are visible, and the velum starts pumping for ventilation. At stage 30 (approx. $30 \mathrm{dpf}$ ), ammocoetes larvae grow and dive into sand or mud to begin filter feeding.

\subsubsection{Development of Hagfish Embryos}

As mentioned, hagfish development remains unknown because there have been few published reports to describe hagfish embryology. Hagfish eggs are large $(2 \mathrm{~cm}) \mathrm{com}-$ pared with those of lampreys (Figure 22.3b) and are encased in a hard, orange eggshell that possesses anchor filaments (hook and loop tape-like structure) at both ends of the long axis to stick to each other, forming a cluster (Figure 22.3c). Little is known about early cleavage, but regarding the large amount of yolk, the cleavage style might be meroblastic. Embryonic development is slow. Surprisingly, the development can be observed from the outside of the eggshell four months after the eggs have been laid, and they appear to take approximately one year to hatch. So far, there are no normal stage tables for 


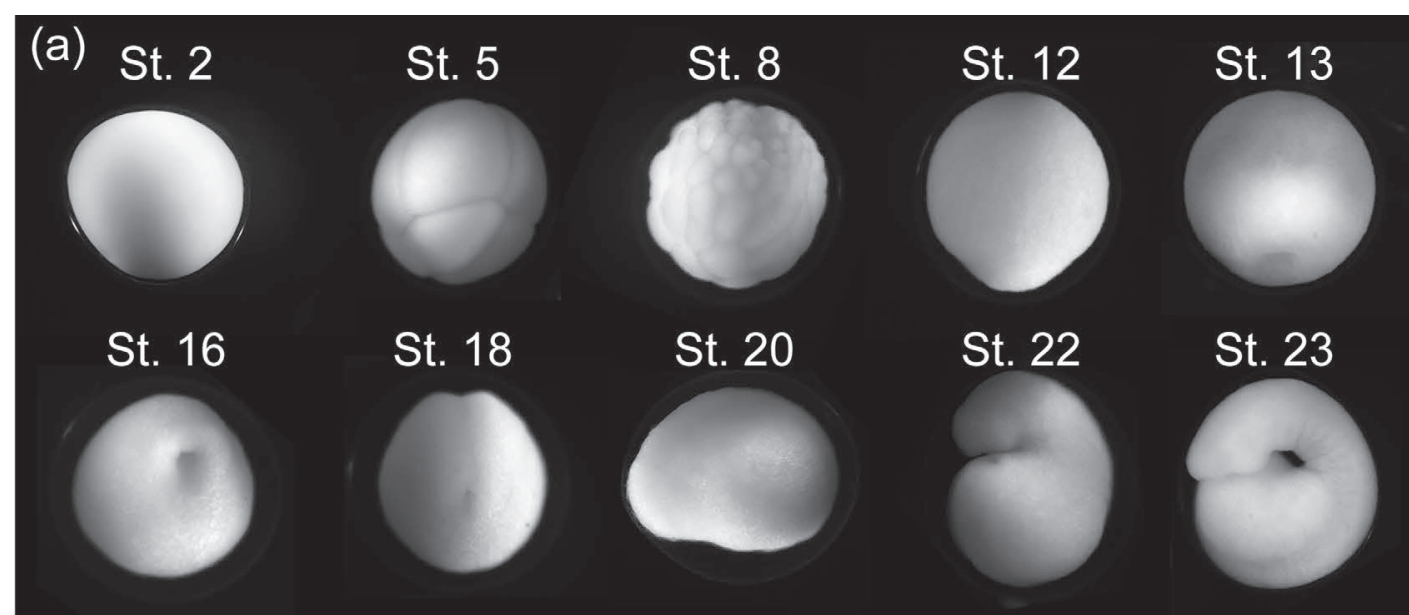

St. 24

St. 26
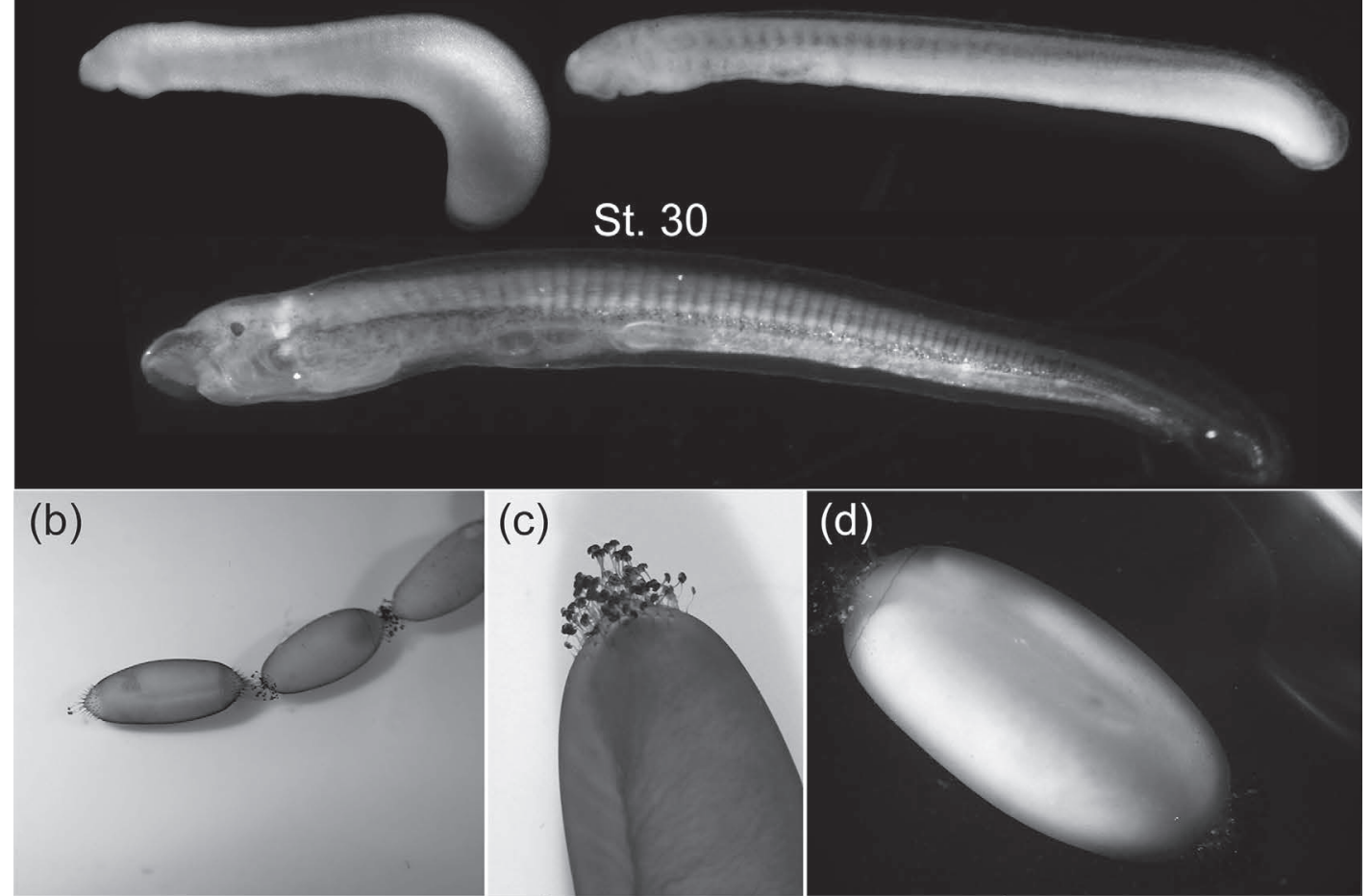

(c)
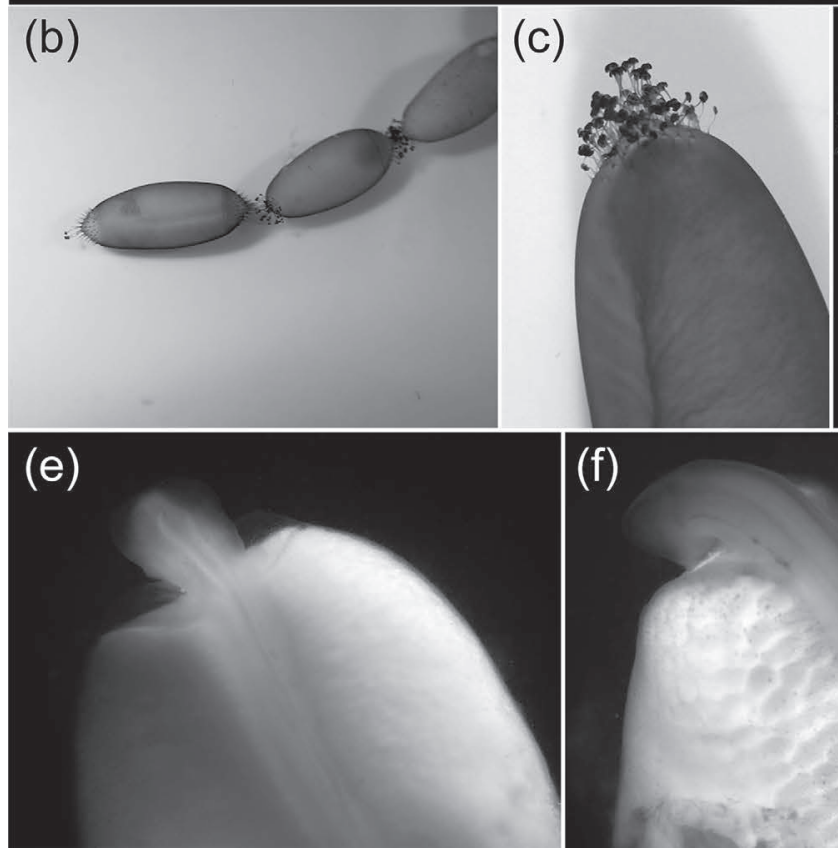

(d)
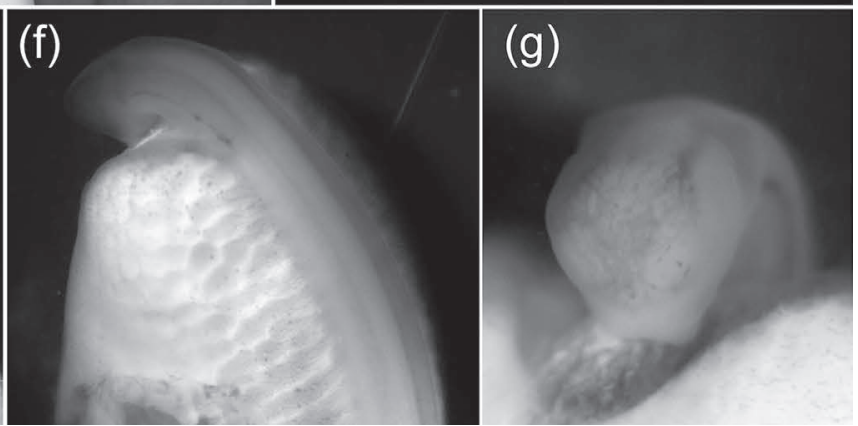

FIGURE 22.3 Embryonic development of the L. camtschaticum (a) and the E. burgeri embryos (b-g). (a) One-cell stage (St. 2), eightcell stage (St.5), morula (St. 8), pre-gastrula (St. 12), early gastrula (St. 13), late gastrula (St. 16), early neurula (St. 18), late neurula (St. 20), head protrusion (St. 22), stomodaeum (St. 23), hatching (St. 24), melanophores (S. 26), ammocoete larva (St. 30). (b) Connected hagfish eggs. (c) "Hook and loop tape"-like structure at both ends of the long axis (d) External view of the hagfish embryo (pharyngula stage). Body axis can be seen, and head region is curved at the edge of the egg. (e) Mid-pharyngula embryo after removal of the eggshell. (f) Late-pharyngula embryo. (g) Anterior view of (f). 
any hagfish species. However, researchers often refer to Dean's figure numbers as describing their developmental stages (Dean 1899; Oisi et al. 2013). The overall development is comparable to that of lampreys. For example, a single median nasohypophyseal (nasal, adenohypophysis) placode arises at the anterior ventral tip of the head. However, hagfish-specific developmental events can be also observed. The stomodeum is closed secondarily by the secondary oropharyngeal membrane. Subsequently, the primary oropharyngeal membrane disappears. This peculiar developmental event caused the endodermal origin of the adenohypophysis to be misidentified (Gorbman 1983). The nasohypophyseal duct opens into the pharynx in hagfish unlike in lampreys. The pharyngeal pouches and surrounding tissues are shifted caudally during the late developmental stage. Juveniles are almost identical to adults except for carrying the yolk sac.

\subsection{ANATOMY}

\subsubsection{LAMPRey ANATOMY}

The body of adult lampreys is cylindrical and covered with scaleless skin (Figure 22.4). On the head, the seven rounded external pharyngeal gill slits open just behind a pair of eyes. A single median nostril (or nasohypophyseal opening) lies on the dorsal midline between the eyes. This duct does not open into the pharynx and ends in a blind sac (Figure 22.4i). A pineal eye, which functions as a photoreceptor, is under the translucent skin, positioned just after the nostril. The oral funnel forms a sucking disk that enables attachment to other fish for feeding or rocks for holding their body in place. There are many horny teeth on the internal surface of the disk. Note that these are not homologous with the enameled teeth in other vertebrates. The dotted lateral lines are present around the head region to detect water flow.
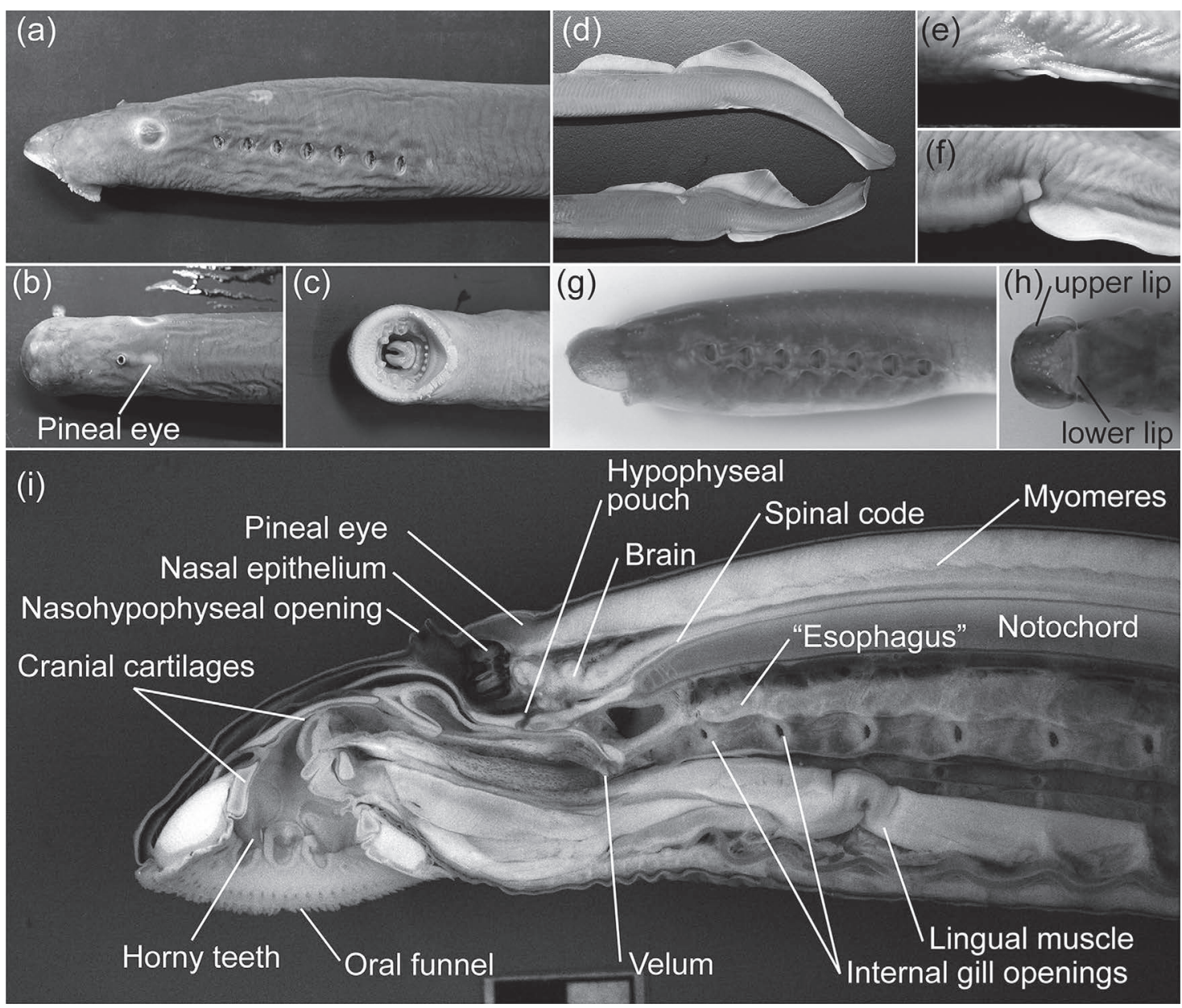

FIGURE 22.4 General anatomy of the lamprey, L. camtschaticum. (a-c) Lateral (a), Dorsal (b), and ventral (c) views of the head. (d) Abdomens of the mature male (above) and female (below). (e) Urogenital papilla of the mature male elongated from the cloaca. (f) Anal fin-like structure of the female. (g, h) Lateral (g) and ventral (h) views of the head of ammocoete larva. (i) Sagittal section of the adult lamprey. Note that the lamprey esophagus is termed the dorsal route of the pharynx (for respiration) and is not homologous with the esophagus in other vertebrates. 
Lampreys do not possess paired fins, but two dorsal fins and caudal fins are present (Figure 22.4d). Usually, it is difficult to distinguish males from females based on external morphology. However, during the mating season, mature males can be distinguished by the presence of urogenital papilla (penis-like protrusion) anterior to the cloaca (Figure 22.4e). In contrast, an anal fin-like structure develops in mature females (Figure 22.4f).

Figure 22.4i shows a sagittal section of the anterior part of adult lampreys. The pharynx is subdivided dorsoventrally. The dorsal part is called the esophagus, and the ventral part is a respiratory tube connected with the gill openings. This subdivision develops during metamorphosis. The velum, positioned between the oral cavity and the pharynx, is a major pumping device during the larval stage but has no respiratory role in adults. True vertebrae are absent, and instead, dorsal cartilaginous arcualias protect the spinal cord. The notochord is fully functional as a supportive organ in the larval and adult body.

The gross anatomy of the lamprey brain is comparable to that of teleosts. The most significant difference between is that lamprey brains have a microscopic cerebellum (Figure 22.5a). In contrast, the pineal organ or epiphysis is well developed. In the inner ear, only two semicircular canals (anterior and posterior) are present, reminiscent of fossil osteostracans (Figure 22.5c; Higuchi et al. 2019).
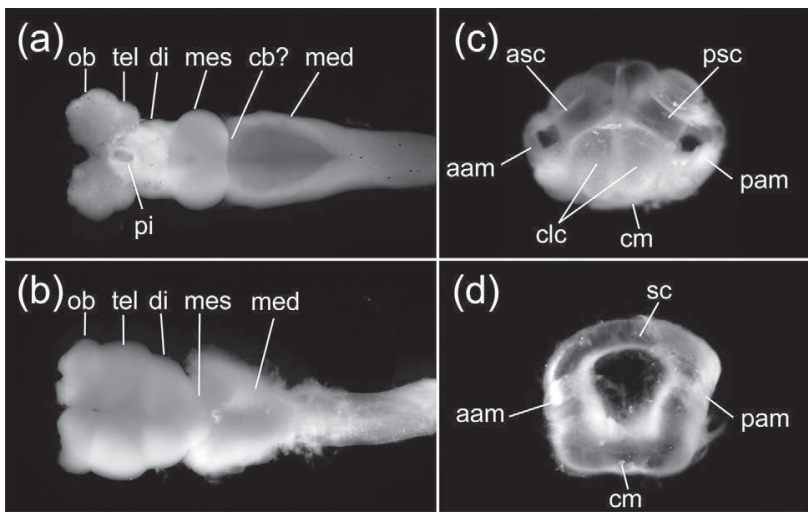

FIGURE 22.5 Brain and semicircular canals of the lamprey $L$. camtschaticum $(\mathrm{a}, \mathrm{c})$ and hagfish E. burgeri $(\mathrm{b}, \mathrm{d})$. asc, anterior semicircular canal; aam, anterior ampulla; cb, cerebellum; clc, ciliated chamber; cm, common macula; di, diencephalon; med, medulla oblongata, mes, mesencephalon; ob, olfactory bulb; pam, posterior ampulla; pi, pineal organ; psc, posterior semicircular canal; sc, semicircular canal; tel, telencephalon.

\subsubsection{HaGfish ANATOMY}

The body of hagfish is eel-like, as in lampreys, and is covered with soft, scaleless skin (Figure 22.1). The rudimentary eyes lack lenses, extraocular muscles and innervating nerves [oculomotor (III), trochlear (IV) and abducens (VI)]. The pineal eye is absent. A few lateral line spots are found around the head surface as shallow grooves in Eptatretus, but these are absent in Myxine (Braun and Northcutt 1997). In contrast to lampreys, the hagfish mouth is normally occluded. They grasp food by protracting and retracting a pair of dental plates. Therefore, their retractor muscle is large (Figure 22.6f). There are six or eight barbels around the mouth innervated by the trigeminal nerve $(\mathrm{V})$ with a sensory role. A single median nostril (or nasohypophyseal opening) opens at the anterior end of the head. Unlike lampreys, this duct does not end in a blind sac but rather opens into the pharynx (Figure 22.6f). This enables water to be taken from the nostril to the gill pouches while closing the mouth. The external gill openings are positioned relatively caudal-ventral compared with those in lampreys (Figure 22.6b). The number of gill openings varies among species, which reflects the number of gill pouches (5-16 pairs). Conversely, each branchial duct of Myxine tends to be fused and opened as a common external aperture on each side. Like lampreys, hagfish also do not possess paired fins, and only a continuous median fin is present on the posterior of the body. It is almost impossible to distinguish sex based on external morphology, but mature females are distinguishable by having large eggs in their abdomen. Velum movement generates a water current and acts as a ventilatory pump. Vertebral elements were traditionally considered to be absent from hagfish, whether cartilage or hard bone. However, recently, cartilaginous tissue (reminiscent of hemal arches in gnathostomes) has been found at the caudal-ventral part of the notochord (Ota et al. 2011). A unique feature is the presence of some accessory hearts in addition to the portal (true) heart. For example, $M$. glutinosa has five accessory hearts (a branchial, two cardinal and two caudal hearts) (Nishiguchi et al. 2016). These are not homologous to the portal heart in other vertebrates because of the lack of cardiac muscles. The accessory hearts are thought to play a role in assisting the portal heart.

The brain of hagfish show curious morphology in contrast to those of other vertebrates (Figure 22.5b). The olfactory bulb and cerebral hemisphere are strikingly larger, but the epiphysis and cerebellum are absent. Owing to this curious shape, it has been extremely difficult to homologize the subregions of the hagfish brain to those of other vertebrates (Conel 1929). In the inner ear, only a pair of single, donutshaped semicircular canals are present (Figure 22.5d). Curiously, this single canal has two ampullae (the detector), whereas each canal has one ampulla in other vertebrates. Recent studies have suggested that the anterior and posterior halves of the canal are homologous to the anterior and posterior canals in lampreys, respectively (Higuchi et al. 2019).

As described, there are many specific features in lampreys and hagfish. It is important not to simply regard these traits as primitive, because they are not ancestral animals, but rather they diverged and lived independently from the jawed vertebrates for over 500 million years and so have traits that they acquired or lost independently. A careful comparison of each trait between the lampreys, hagfish and jawed vertebrates would allow us to depict the ancestry of early vertebrates (Sugahara et al. 2017). 

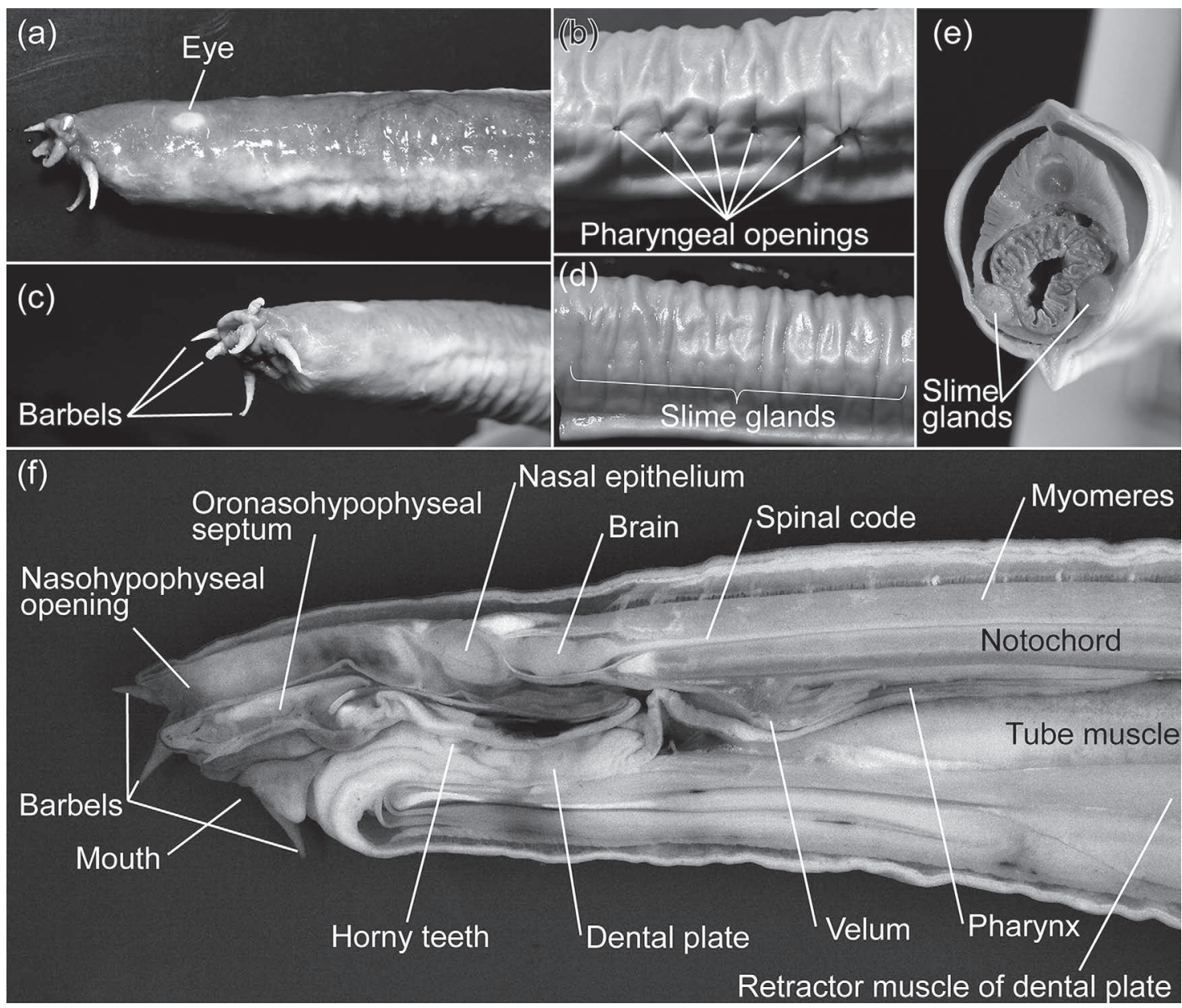

FIGURE 22.6 General anatomy of the hagfish, E. burgeri. The skin is artificially shrunk and shows bellow-like wrinkles by formalin fixation. (a, c) Lateral (a) and anterior (b) views of the head. (b) Pharyngeal openings on the ventral lateral body surfaces. Note that the last opening on the left side is slightly larger, called the pharyngocutaneous opening. This duct is directly connected to the pharynx and also fused with the common efferent gill duct on the left side. (d, e) Slime glands on the ventral lateral sides of the body. (f) Sagittal section.

\subsection{GENOMIC DATA}

\subsubsection{Genomic Features of the Cyclostomes}

All lamprey karyotypes are characterized by small, dotshaped chromosomes (microchromosomes). In general, they have 100 or more chromosomes in somatic diploid cells. For example, germline diploid cells have 198 chromosomes in P. marinus and 168 chromosomes in L. camtschaticum (Ishijima et al. 2017). Males and females have the same number of chromosomes. The sex determination system is unclear but may be determined by the growth rate during the larval period (Johnson et al. 2017).

The genomic sequences of lampreys have been less well understood until recently because they contain high GC content in the coding region, which prevents sequencing by the traditional Sanger method and PCR-based gene cloning. Although the overall GC content is $46 \%$ in the P. marinus genome, the GC content in the coding regions is markedly higher (61\%) than that in noncoding regions (Smith et al.
2013). Four-fold degenerate sites $\left(\mathrm{GC}_{4}\right)$ are especially high (around 70-90\%) compared with those in hagfish (40-60\%) (Kuraku et al. 2006). Another difficulty with sequencing is that the lamprey genome possesses highly repetitive elements that prevent the assembly of each fragment by next-generation sequencing. Recently, these difficulties have been overcome by optimizing the computational assembly that allowed us to assemble fragments from next-generation sequence data (Smith et al. 2018). Currently, the lamprey genome sequence is available from three species ( $P$. marinus, L. camtschaticum and Entosphenus tridentatus (Table 22.1). Transcriptome data sets are also available for $P$. marinus and $L$. camtschaticum.

The chromosome number of hagfish is much lower than that of lampreys. For example, 52 are found in the diploid testis cells of E. burgeri, 48 in E. stoutii and 44 in M. glutinosa. Males and females have the same number of chromosomes. Sex determination is unknown. Recently, the genome sequence of the hagfish $E$. burgeri has been made available (Table 22.1). 
TABLE 22.1

Major available genome resources in lampreys and hagfishes

\begin{tabular}{|c|c|c|c|c|}
\hline Name & (Human) & Arctic lamprey & Sea lamprey & Inshore hagfish \\
\hline Species & Homo sapiens & Lethenteron camtschaticum & Petromyzon marinus & Eptatretus burgeri \\
\hline Source & & testis & sperm & testis \\
\hline $\begin{array}{l}\text { Total sequence } \\
\text { length (bp) }\end{array}$ & $3,099,706,414$ & $1,030,662,718$ & $1,089,050,413$ & $2,608,383,542$ \\
\hline Scaffolds (bp) & $67,794,873$ & 86,125 & 1,434 & 10,846 \\
\hline N50 scaffold size & $67,794,873$ & $1,051,965$ & $12,997,950$ & \\
\hline $\begin{array}{l}\text { Estimated } \\
\text { genome size }\end{array}$ & $3.1 \mathrm{~Gb}$ & $1.6 \mathrm{~Gb}$ & N/A & $2.9 \mathrm{~Gb}$ \\
\hline Coverage & & $20.0 x$ & $62.36 \mathrm{x}$ & $210 x$ \\
\hline Reference & $\begin{array}{l}\text { https://www.ncbi.nlm. } \\
\text { nih.gov/assembly/ } \\
\text { GCA_000466285.1/ }\end{array}$ & $\begin{array}{l}\text { https://www.ncbi.nlm.nih.gov/ } \\
\text { assembly/GCF_010993605.1 }\end{array}$ & $\begin{array}{l}\text { https://www.ncbi.nlm.nih.gov/ } \\
\text { assembly/GCA_900186335.2 }\end{array}$ & $\begin{array}{l}\text { https://www.ncbi.nlm. } \\
\text { nih.gov/assembly/ } \\
\text { GCF_000001405.39 }\end{array}$ \\
\hline
\end{tabular}

\subsubsection{Chromosome Elimination and Programmed Sequence Loss in Cyclostomes}

Chromosome elimination is a process in which some chromosomes are discarded during embryogenesis, whereas germline cells retain all chromosomes (Figure 22.7a). This process is widely seen in protostomes, such as nematodes and arthropods. In vertebrates, only hagfish were observed to expel some chromosomes from presumptive somatic cells. In E. burgeri, there are 36 chromosomes in somatic cells and 52 in the germline cells, suggesting that 16 chromosomes (20.9\% DNA content) are eliminated during embryogenesis (Kohno et al. 1998; Figure 22.7b). These chromosomes contain highly repetitive DNA sequences and are highly heterochromatinized in germ cells (Kohno et al. 1998). Moreover, this event was recently observed in the lamprey $P$. marinus (Timoshevskiy et al. 2019), suggesting that this phenomenon is shared by both cyclostome lineages.

Another type of genome rearrangement is seen in cyclostomes, namely programmed sequence loss (Figure 22.7a). In P. marinus, the DNA content of haploid sperm is $2.31 \mathrm{pg}$, and that of blood cells is $1.82 \mathrm{pg}$ ( $>20 \%$ of the genome, or 0.5 billion base pairs) (Smith et al. 2009); Figure 22.6c). Discarded sequences contain not only several different repetitive elements but also transcribed loci in the developmental stage. In hagfish, heterochromatinized regions that contain repetitive elements are widely eliminated (Kohno et al. 1998). Altogether, lampreys and hagfish undergo both genome rearrangement mechanisms and thus will provide critical insights into the evolution of genome rearrangement in the vertebrate lineage.

\subsubsection{Hox Clusters and Whole-Genome Duplication}

Ohno (1970) proposed that early vertebrates underwent two rounds of whole-genome duplication (2R WGD). This hypothesis has been supported by the number of Hox clusters. Amphioxus have a single Hox gene cluster in contrast to the four clusters in mammals (Figure 22.8). Moreover, teleosts might have experienced another WGD. This suggests that 2R WGD might have occurred in the ancestry of vertebrates. However, the timing of the WGD in the pre- or postdivergence of the cyclostomes remains unclear. Interestingly, recent genomic studies have revealed that both lampreys and hagfish have at least six Hox gene clusters in their genome (Mehta et al. 2013; Pascual-Anaya et al. 2018) (Figure 22.8). These results suggest that at least one independent (whole or partial) genome duplication event might have occurred in the cyclostome lineage, but it is still unclear whether cyclostomes share the gnathostome 2R, 1R or 0R of WGD (Figure 22.8).

\subsection{FUNCTIONAL APPROACHES: TOOLS FOR MOLECULAR AND CELLULAR ANALYSES}

\subsubsection{AdVANTAGES OF LAMPREY Developmental Research}

As it is difficult to obtain fertilized eggs, experimental embryology with hagfish has been limited to histological or gene and protein expression analyses (Oisi et al. 2015). Therefore, this topic focuses on the functional analysis of lamprey developmental biology (for normal histology, in situ hybridization, and immunohistochemical techniques on lamprey embryos, see Sugahara et al. 2015). Since the breeding season for lampreys occurs once a year, there are not many opportunities for experiments to be carried out compared with zebrafish and Xenopus. However, lampreys have some advantages over other model organisms. More than 10,000 eggs can be obtained from one female during a single artificial fertilization event. Hundreds of eggs and embryos can be incubated in a small plastic dish with fresh water (Figure 22.9a). Most 


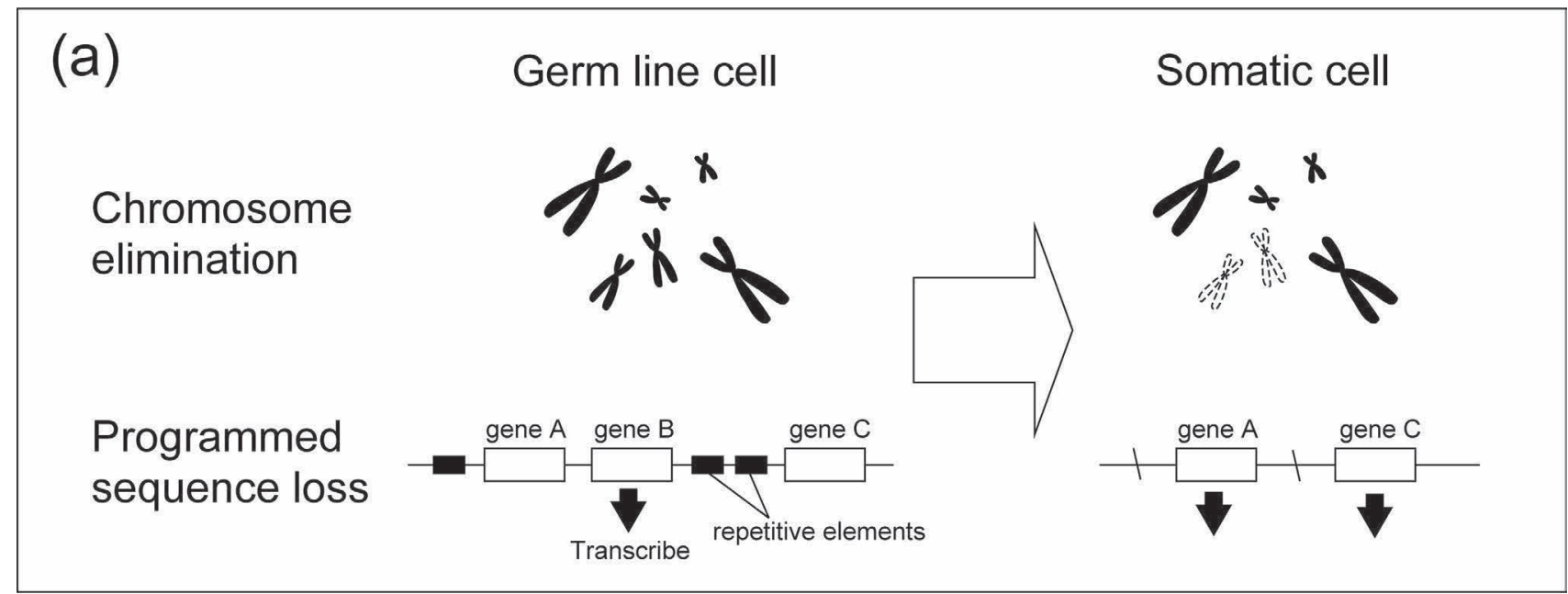

(b)

\begin{tabular}{llll} 
Species & $\begin{array}{l}\text { Germ } \\
\text { cell }\end{array}$ & $\begin{array}{l}\text { Somatic } \\
\text { cell }\end{array}$ & $\begin{array}{l}\% \text { of eliminated } \\
\text { DNA amount }\end{array}$ \\
\hline
\end{tabular}

$\begin{array}{llll}\text { E. stoutii } & 48 & 34 & 52.8 \% \\ \text { E. burgeri } & 52 & 36 & 20.9 \% \\ \text { P. atami } & 48 & 34 & 40.0 \% \\ \text { M. glutinosa } & 44 & 28 & 43.5 \%\end{array}$

(C) DNA content $(\mathrm{pg})$

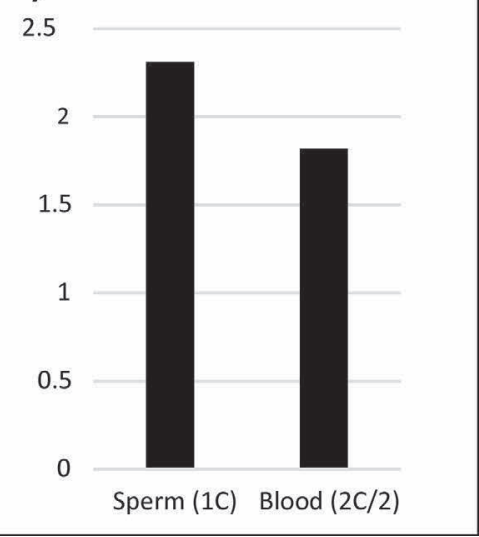

FIGURE 22.7 Genome rearrangement in cyclostomes. (a) Overview of the chromosome elimination and programmed sequence loss (b) Reduction of the chromosomes in hagfish species (c) Reduction of DNA content during development in the sea lamprey, P. marinus. $1 \mathrm{C}$ and $2 \mathrm{C} / 2$ indicates haploid genome size. Recent studies have revealed that both lampreys and hagfish undergo both reduction mechanisms. ([a] Modified from Semon et al. 2012; [b] based on Kohno et al. 1998; [c] adapted from Smith et al. 2009.)

experimental techniques developed for zebrafish or Xenopus can also be applied to lamprey embryos. In particular, lamprey eggs are particularly amenable to microinjection. They have a double chorion, which prevents them from exploding due to the water surface tension when eggs are removed from the water, and therefore, the eggs can be injected with liquids on dry mesh (Figure 22.9c, d). In addition, unlike fastdeveloping model organisms, the slow cleavage of lamprey embryos allows the injection of many eggs for a long time (over $5 \mathrm{~h}$ ) during one or two cell stages.

\subsubsection{Drug Application}

Drug application in lamprey embryos is the easiest method for investigating certain gene functions or signaling pathways. Eggs or embryos can be exposed to an adequate concentration of the drug by immersion (Figure 22.9b). For instance, the following drugs have been used and showed certain effects on lamprey embryos: SU5402 for the blocking of FGF signaling
(Tocris Bioscience; Sugahara et al. 2011), U0126 for the inhibition of MAP kinases (Tocris Bioscience; Jandzik et al. 2014), Cyclopamine for Hedgehog signaling (Calbiochem; Sugahara et al. 2011), DAPT for the Notch pathway inhibitor (Lara-Ramirez et al. 2019) and SB-505124 for the Nodal antagonist (Abcam; Lagadec et al. 2015). All-trans retinoic acid has also been used for enhancing retinoic acid signaling in a dose-dependent manner (Kuratani et al. 1998).

\subsubsection{Morpholino Antisense Oligomers}

Morpholino antisense oligomers (MOs) are useful tools for knocking down gene function in developmental biology research as conceived by Gene Tools LLC. The MOs are usually 25-mer nucleic acid analogs synthesized to bind to complementary target RNA. When MO binds to the $5^{\prime}$-UTR of mRNA, it can prevent translation of the coding region of the target gene by interfering with the progression of the ribosome. Once MO binds to the border of the 


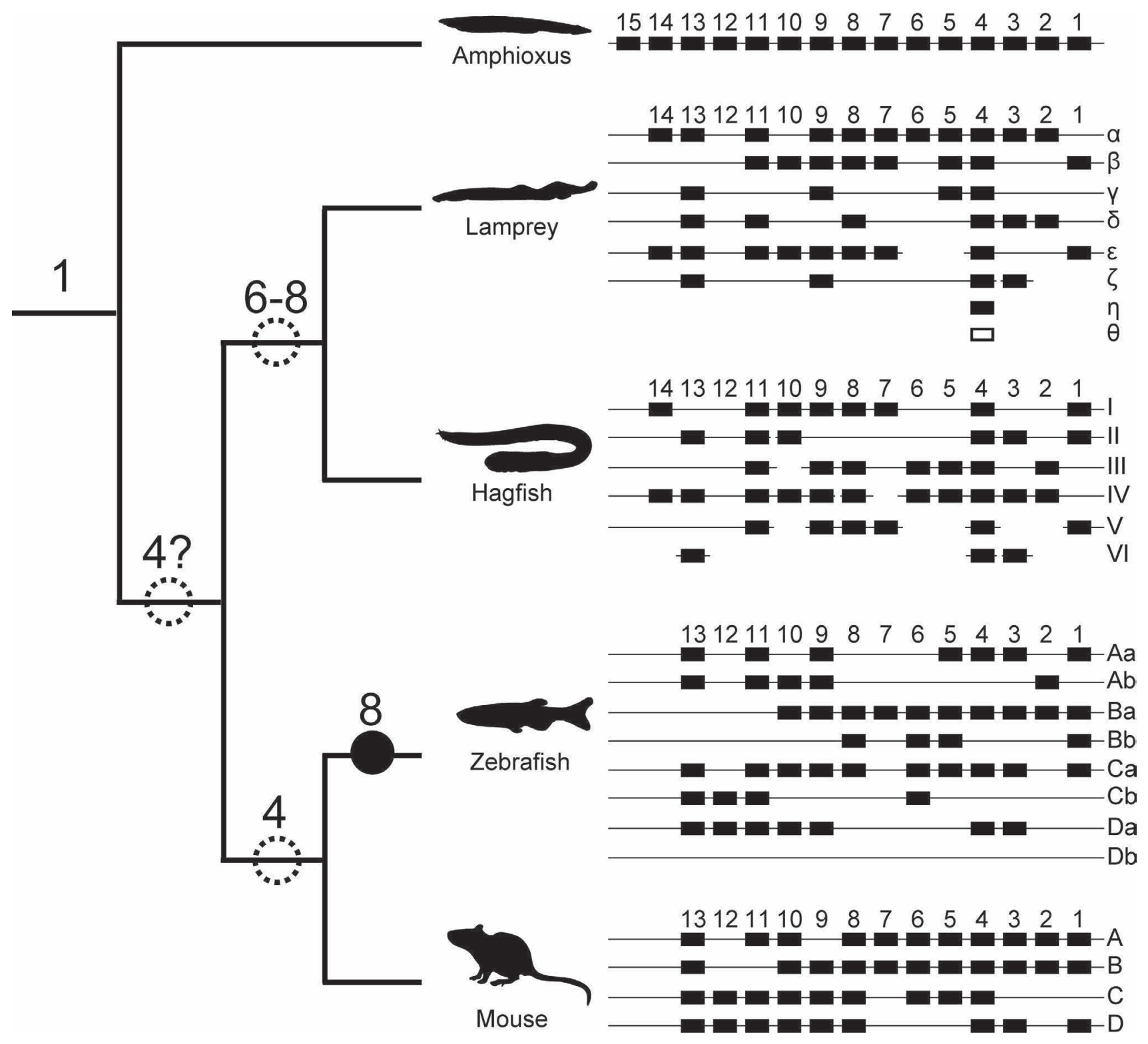

FIGURE 22.8 Hox genes in vertebrates and whole genome duplications. Dotted circles indicate possible whole genome duplication events. Black circle indicates teleost-specific whole genome duplication. Note that although zebrafish do not have HoxDb clusters, some teleost species (e.g. medaka and fugu) retain some genes belonging to HoxDb. (Adapted from Pascual-Anaya et al. 2018.)

introns on pre-mRNA, it can block splicing by interfering with a splice-directing small nuclear ribonucleoprotein (snRNP) complex. For investigating lamprey embryology, researchers can inject MOs by microinjection at the one- or two-cell stages. Five-mismatch MOs can be used as control experiments to distinguish side effects. When MOs are injected into one blastomere at the two-cell stage, the effect could be observed at only one side of the embryo. This enables easy comparison of morphological changes or gene expression (Nikitina et al. 2009).

\subsubsection{CRISPR/Cas9 Gene Editing}

CRISPR/Cas9 gene editing is a recently developed genetic engineering tool in molecular biology. The CRISPR/Cas9 system was originally a bacterial defense mechanism and was adapted to target mutagenesis in eukaryote genomes. In particular, it is a strong tool for producing knockout lines of animals, such as mice, flies, zebrafish and Xenopus. Mutations can be generated simply by injecting Cas9 (endonuclease) mRNA with a synthetic guide RNA into fertilized eggs. Once the Cas9-gRNA complex binds to the DNA target, Cas9 cleaves both strands. The resulting double-strand break is then repaired, but it frequently causes small insertions or deletions at the breaking sites, resulting in amino acid deletions, insertions or frameshift mutations of the target gene. Unfortunately, it is not practical to produce $F_{1}$ or $F_{2}$ generations of lampreys, and analysis has to be carried out at $\mathrm{F}_{0}$. Usually, $\mathrm{F}_{0}$ shows a mosaic for the mutation because CRISPR/Cas9 persists and functions beyond the one-cell 


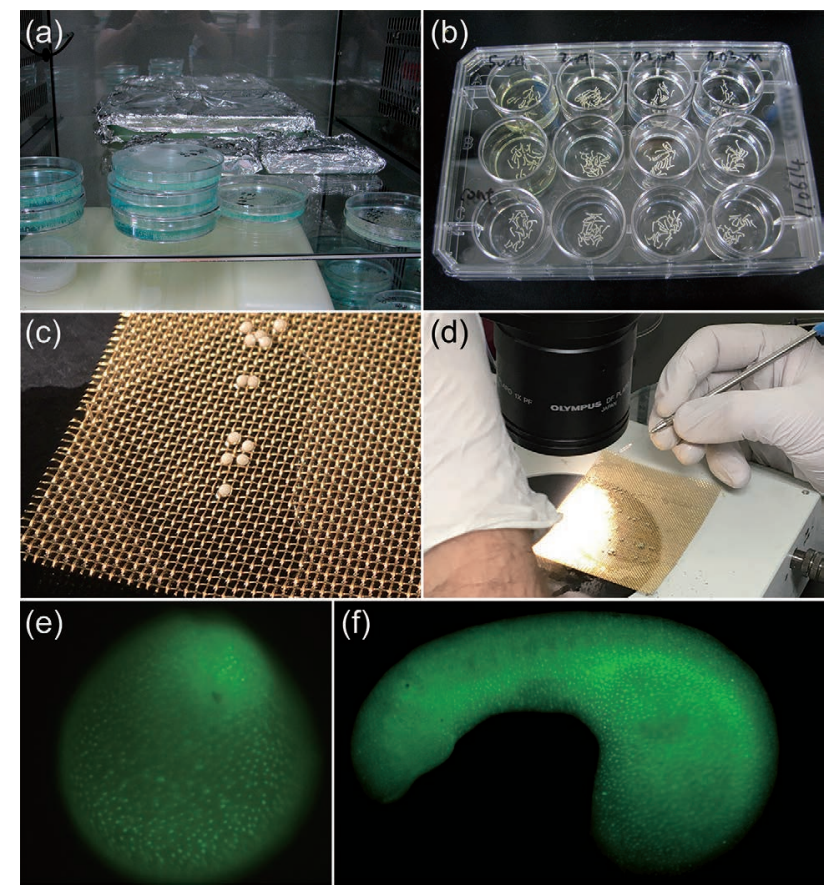

FIGURE 22.9 Embryonic manipulation of lamprey embryos. (a) Incubation of lamprey embryos in 9-cm dishes. Hundreds of embryos can be kept in one dish. Blue water is the $10 \%$ Steinberg's solution containing $0.6 \mathrm{ppm}$ of methylene blue to prevent bacterial growth. (b) Drug application in lamprey embryos; 20-30 embryos can be exposed to a certain concentration of drugs in each 12-well dish. (c,d) Microinjection in lamprey embryos. The sieve mesh size is $0.61 \mathrm{~mm}$, and wire diameter is $0.23 \mathrm{~mm}$. (e,f) KAEDE (photoconvertible protein) expression in lamprey embryos (stages 18 and 23). KAEDE mRNA combined with nuclear localized signal injected in one-cell eggs after fertilization. The expression can be seen only in each cell nucleus and lasts at least until hatching stage.

stage. However, several reports have shown that CRISPR/ Cas9-injected $\mathrm{F}_{0}$ embryos effectively disrupted target genes, even though each cell was differentially mutated (Square et al. 2015).

\subsection{CHALLENGING QUESTIONS}

Finally, I suggest some challenging questions in the developmental and genomic fields from an evolutionary perspective.

\subsubsection{Cerebellar Evolution}

The cerebellum plays an essential role in controlling coordinated movements as well as cognitive and emotional functions in humans. All living gnathostomes have distinct, three-layered cerebella (granular, Purkinje and molecular layers). However, lampreys have an undifferentiated cerebellum, which is only visible as a dorsal lip at the anterior end of the rhombencephalon. They do not have a layered structure, but some cerebellum-specific neuron subtypes have been found. In contrast, the presence of the cerebellum in hagfish is uncertain. Recently, Sugahara et al. (2016) reported on the gene expression in lamprey and hagfish embryos that is essential for cerebellar development. When and how the cerebellum was established and acquired a three-layered structure during vertebrate evolution are intriguing questions. A comparison of cerebellar development between cyclostomes and gnathostomes would answer this question. See Sugahara et al. (2017) for detailed information.

\subsubsection{Evolution of the Paired Nostrils}

Most fossil jawless fish have a single median nostril, and cyclostomes might also retain this ancestral condition. During development, the gnathostome nasal placode is generated as paired and separated from the hypophyseal placode (Rathke's pouch). In contrast, the median nasal placode and hypophyseal placode arise as a single ectodermal thickening in lampreys and hagfish. The separation of the nasohypophyseal placode and subsequent changes in the migration of neural crest cells might be a key innovation for the acquisition of the jaw (Kuratani et al. 2001).

\subsubsection{Origin of the Paired Appendages}

Cyclostomes do not possess paired fins that are homologous to human arms and legs. So far, two major theories have been proposed to explain the origin of paired fins. The fin-fold theory posits that paired fins evolved from a longitudinal paired fin-fold. Anaspida, an early Silurian fish, might have had paired folds on the ventral side of the body (Janvier 1996). Another theory is the gill-arch theory that posits that the pectoral fins were the result of the transformation or co-option of the gill arches. It may well be the case that vertebrates acquired the pectoral fin first (see Osteostracans in Figure 22.2). It would be interesting to investigate whether cyclostomes have the potential to form paired appendages. In lamprey embryos, different distribution patterns of the lateral plate mesoderm, which contributes to limb growth, have been reported (Tulenko et al. 2013).

\subsubsection{Evolution of the Thyroid Gland}

The ammocoetes larvae of lampreys have an endostyle under the pharynx as a secreting organ for filter feeding. Nonvertebrate chordates, Amphioxus and ascidians also possess this organ. During metamorphosis, the lamprey endostyle changes into the thyroid gland. Therefore, it is thought that the chordate endostyle is homologous to the vertebrate thyroid gland and transitioned from an endostyle to the thyroid in lamprey evolutionary history (Ogasawara et al. 2001). This theory is based on the homology of the endostyle between lampreys and non-vertebrate chordates. However, the homology of the endostyle remains unclear. In addition, although the hagfish undergoes direct development and thus does not have an endostyle, there is only one much older study regarding the thyroid gland (Stockard 1906). Detailed analysis of 
hagfish thyroid gland development would shed light on this question.

\subsubsection{Timing of Whole-Genome Duplication}

As noted previously, hagfish and lampreys possess at least six Hox clusters (Mehta et al. 2013; Pascual-Anaya et al. 2018). Since the homology and relationship between each cluster and gnathostome clusters remain unclear, it is yet to be determined whether the two rounds of WGDs that gnathostome experienced occurred before or after the divergence of the cyclostomes. Deep, detailed comparative synteny analysis of cyclostome genomes would lead to a clearer understanding of the evolution of the vertebrate genome.

\section{ACKNOWLEDGMENTS}

I thank Shigeru Kuratani and his past and current laboratory members for cyclostome research, Noboru Sato and Hiroshi Nagashima for lamprey sampling and Osamu Kakitani for hagfish sampling.

\section{BIBLIOGRAPHY}

Bardack, D. 1991. First fossil hagfish (myxinoidea): A record from the Pennsylvanian of Illinois. Science 254 (5032):701-703.

Braun, C.B., and R.G. Northcutt. 1997. The lateral line system of hagfishes (Craniata: Myxinoidea). Acta Zoologica 78 (3):247-268.

Chang, M.M., Wu, F., Miao, D., and J. Zhang. 2014. Discovery of fossil lamprey larva from the Lower Cretaceous reveals its three-phased life cycle. Proceedings of the National Academy of Sciences of the United States of America 111 (43):15486-15490.

Conel, J.L. 1929. The development of the brain of Bdellostoma stouti 1: External growth changes. Journal of Comparative Neurology 47 (3):343-403.

Dean, B. 1899. On the embryology of Bdellostoma stouti: A general account of myxinoid development from the egg and segmentation to hatching. Festschrift zum 70ten Geburststag Carl von Kupffer:220-276.

Duméril, C. 1806. Zoologie analytique, ou méthode naturelle de classification des animaux, Rendue plus facile a l'Aide de Tableaux Synoptiques. Paris: Allais.

Dupret, V., Sanchez, S., Goujet, D., Tafforeau, P., and P.E. Ahlberg. 2014. A primitive placoderm sheds light on the origin of the jawed vertebrate face. Nature 507 (7493):500-3.

Evans, T.M., and J.E. Bauer. 2016. Identification of the nutritional resources of larval sea lamprey in two Great Lakes tributaries using stable isotopes. Journal of Great Lakes Research 42 (1):99-107.

Fernholm, B., Norén, M., Kullander, S.O., et al. 2013. Hagfish phylogeny and taxonomy, with description of the new genus Rubicundus (Craniata, Myxinidae). Journal of Zoological Systematics Evolutionary Research 51 (4):296-307.

Fudge, D.S., Herr, J.E., and T.M. Winegard. 2016. Hagfish Slime, Hagfish Biology. New York: CRC Press.

Gai, Z., Donoghue, P.C., Zhu, M., Janvier, P., and M. Stampanoni. 2011. Fossil jawless fish from China foreshadows early jawed vertebrate anatomy. Nature 476 (7360):324-327.
Gess, R.W., Coates M.I., and B.S. Rubidge. 2006. A lamprey from the Devonian period of South Africa. Nature 443 (7114):981-984.

Gorbman, A. 1983. Early development of the hagfish pituitarygland: Evidence for the endodermal origin of the adenohypophysis. American Zoologist 23 (3):639-654.

Gustafson, G. 1935. On the biology of Myxine glutinosa L. Arkiv Zool 28:1-8.

Heimberg, A.M., Cowper-Sal-lari, R., Sémon, M., Donoghue, P.C., and K.J. Peterson. 2010. microRNAs reveal the interrelationships of hagfish, lampreys, and gnathostomes and the nature of the ancestral vertebrate. Proceedings of the National Academy of Sciences of the United States of America 107 (45):19379-19383.

Higuchi, S., Sugahara, F., Pascual-Anaya J., Takagi W., Oisi, Y., and S. Kuratani. 2019. Inner ear development in cyclostomes and evolution of the vertebrate semicircular canals. Nature 565 (7739):347-350.

Hirasawa, T., Oisi, Y., and S. Kuratani. 2016. Palaeospondylus as a primitive hagfish. Zoological Letters 2 (1):20.

Ichikawa, T., Kobayashi, H., and M. Nozaki. 2000. Seasonal migration of the hagfish, Eptatretus burgeri, Girard. Zoological Science 17 (2):217-223.

Ishijima, J., Uno, Y., Nunome, M. Nishida, C., Kuraku, S., and Y. Matsuda. 2017. Molecular cytogenetic characterization of chromosome site-specific repetitive sequences in the Arctic lamprey (Lethenteron camtschaticum, Petromyzontidae). DNA Research 24 (1):93-101.

Jandzik, D., Hawkins, M.B., Cattell, M.V., Cerny, R., Square, T.A., and D.M. Medeiros. 2014. Roles for FGF in lamprey pharyngeal pouch formation and skeletogenesis highlight ancestral functions in the vertebrate head. Development 141 (3):629-638.

Janvier, P. 1996. Early Vertebrates. Oxford: Oxford University Press. Johnson, N.S., Swink, W.D., and T.O. Brenden. 2017. Field study suggests that sex determination in sea lamprey is directly influenced by larval growth rate. Proceedings of the Royal Society: Biological Sciences 284 (1851).

Johanson, Z., Smith, M., Sanchez, S., Senden, T., Trinajstic, K., and C. Pfaff. 2017. Questioning hagfish affinities of the enigmatic Devonian vertebrate Palaeospondylus. Royal Society Open Science 4 (7):170214.

Jørgensen, J.M., Lomholt, J.P., Weber R.E., and H. Malte. 2012. The Biology of Hagfishes. London: Springer Science \& Business Media.

Kataoka, T. 1985. Studies on the propagation of Lethenteron camtschaticum (IV) (in Japanese). Research Reports of Niigata Prefectural Freshwater Fisheries Experiment Station 12:23-27.

Kohno, S., Kubota, S., and Y. Nakai. 1998. Chromatin diminution and chromosome elimination in hagfishes. In The Biology of Hagfishes. London: Springer.

Kuraku, S., Hoshiyama, D., Katoh, K., Suga, H., and T. Miyata. 1999. Monophyly of lampreys and hagfishes supported by nuclear DNA-coded genes. Journal of Molecular Evolution 49 (6):729-735.

Kuraku, S., Ishijima, J., Nishida-Umehara, C., Agata, K., Kuratani, S., and Y. Matsuda. 2006. cDNA-based gene mapping and GC3 profiling in the soft-shelled turtle suggest a chromosomal size-dependent GC bias shared by sauropsids. Chromosome Research 14 (2):187-202.

Kuraku, S., and S. Kuratani. 2006. Time scale for cyclostome evolution inferred with a phylogenetic diagnosis of hagfish and lamprey cDNA sequences. Zoological Science 23 (12):1053-1064.

Kuratani, S., Nobusada, Y., Horigome, N., and Y. Shigetani. 2001. Embryology of the lamprey and evolution of the vertebrate jaw: Insights from molecular and developmental 
perspectives. Philosophical Transactions of the Royal Society B: Biological Sciences 356 (1414):1615-1632.

Kuratani, S., Ueki, T., Hirano, S., and S. Aizawa. 1998. Rostral truncation of a cyclostome, Lampetra japonica, induced by all-trans retinoic acid defines the head/trunk interface of the vertebrate body. Developmental Dynamics 211 (1):35-51.

Lagadec, R., Laguerre, L., Menuet, A., Amara, A., Rocancourt, C., Péricard, P., Godard, B.G., Rodicio, M.C., RodriguezMoldes, I., Mayeur, H., Rougemont, Q., Mazan, S., and A. Boutet. 2015. The ancestral role of nodal signalling in breaking L/R symmetry in the vertebrate forebrain. Nature Communications 6.

Lara-Ramirez, R., Pérez-González, C., Anselmi, C., Patthey, C., and S.M. Shimeld. 2019. A Notch-regulated proliferative stem cell zone in the developing spinal cord is an ancestral vertebrate trait. Development 146 (1).

Linnaeus, C. 1758. Systema naturae. Vol. 1. Stockholm: Stockholm Laurentii Salvii.

Løvtrup, S. 1977. The Phylogeny of Vertebrates. New York: John Wiley.

Mallatt, J., and J. Sullivan. 1998. 28S and 18S rDNA sequences support the monophyly of lampreys and hagfishes. Molecular Biology and Evolution 15 (12):1706-1718.

Mehta, T.K., Ravi, V., Yamasaki, S., et al. 2013. Evidence for at least six Hox clusters in the Japanese lamprey (Lethenteron japonicum). Proceedings of the National Academy of Sciences 110 (40): 16044-16049.

Morris, S.C., and J.B. Caron. 2014. A primitive fish from the Cambrian of North America. Nature 512 (7515):419-422.

Müller, A. 1856. XXVI: On the development of the lampreys. Annals and Magazine of Natural History 18 (106):298-301.

Nelson, J.S., Grande, T.C., and M.V.H. Wilson. 2016. Fishes of the World. Hoboken, NJ: John Wiley \& Sons.

Nikitina, N., Bronner-Fraser, M., and T. Sauka-Spengler. 2009. The sea lamprey Petromyzon marinus: A model for evolutionary and developmental biology. Cold Spring Harbor Protocols 2009 (1):pdb.emo113.

Nishiguchi, Y., Tomita, T., Sato, et al. 2016. Examination of the hearts and blood vascular system of Eptatretus okinoseanus using computed tomography images, diagnostic sonography, and histology. International Journal of Analytical BioScience 4 (3):46-54.

Ogasawara, M., Shigetani, Y., Suzuki, S., Kuratani, S., and N. Satoh. 2001. Expression of thyroid transcription factor-1 (TTF-1) gene in the ventral forebrain and endostyle of the agnathan vertebrate, Lampetra japonica. Genesis 30 (2):51-58.

Ohno, S. 1970. Evolution by Gene Duplication. New York: Springer Science \& Business Media.

Oisi, Y., Kakitani, O., Kuratani, S., and K.G. Ota. 2015. Analysis of embryonic gene expression patterns in the hagfish. In In Situ Hybridization Methods. New York: Springer.

Oisi, Y., Ota, K.G., Kuraku, S., Fujimoto, S., and S. Kuratani. 2013. Craniofacial development of hagfishes and the evolution of vertebrates. Nature 493 (7431):175-180.

Ota, K.G., Fujimoto, S., Oisi, Y., and S. Kuratani. 2011. Identification of vertebra-like elements and their possible differentiation from sclerotomes in the hagfish. Nature Communications 2:373.

Ota, K.G., Kuraku, S., and S. Kuratani. 2007. Hagfish embryology with reference to the evolution of the neural crest. Nature 446 (7136):672-675.
Pascual-Anaya, J., Sato, I., Sugahara, F., et al. 2018. Hagfish and lamprey Hox genes reveal conservation of temporal colinearity in vertebrates. Nature Ecology Evolution 2 (5):859-866.

Sémon, M., Schubert, M., and V. Laudet. 2012. Programmed genome rearrangements: In lampreys, all cells are not equal. Current Biology 22 (16):R641-643.

Smith, J.J., Antonacci, F., Eichler, E.E., and C.T. Amemiya. 2009. Programmed loss of millions of base pairs from a vertebrate genome. Proceedings of the National Academy of Sciences of the United States of America 106 (27):11212-11217.

Smith, J.J., Kuraku, S., Holt, C., et al. 2013. Sequencing of the sea lamprey (Petromyzon marinus) genome provides insights into vertebrate evolution. Nature Genetics 45 (4):415-421, 421e1-421e2.

Smith, J.J., Timoshevskaya, N., Ye, C., et al. 2018. The sea lamprey germline genome provides insights into programmed genome rearrangement and vertebrate evolution. Nature Genetics 50 (2):270-277.

Square, T., Romášek, M., Jandzik, D., Cattell, M.V., Klymkowsky, M., and D.M. Medeiros. 2015. CRISPR/Cas9-mediated mutagenesis in the sea lamprey Petromyzon marinus: A powerful tool for understanding ancestral gene functions in vertebrates. Development 142 (23):4180-4187.

Stockard, C.R. 1906. The development of the thyroid gland in Bdellostoma stouti. Anatomischer. Anzeiger. 29:91-99.

Sugahara, F., Aota, S., Kuraku, S., et al. 2011. Involvement of hedgehog and FGF signalling in the lamprey telencephalon: Evolution of regionalization and dorsoventral patterning of the vertebrate forebrain. Development 138 (6):1217-1226.

Sugahara, F., Murakami, Y., Pascual-Anaya, P., and S. Kuratani. 2017. Reconstructing the ancestral vertebrate brain. Development, Growth \& Differentiation 59 (4):163-174.

Sugahara, F., Pascual-Anaya, J., Oisi, Y., et al. 2016. Evidence from cyclostomes for complex regionalization of the ancestral vertebrate brain. Nature 531 (7592):97-100.

Sugahara, F., Yasunori M., and S. Kuratani. 2015. Gene expression analysis of lamprey embryos. In In Situ Hybridization Methods. New York: Springer.

Sumich, J.L. 1992. Benthic communities. In Introduction to the Biology of Marine Life. Dubuque, Iowa: Wn. C. Brown.

Tahara, Y. 1988. Normal stages of development in the lamprey, Lampetra reissneri (Dybowski). Zoological Science 5 (1): 109-118.

Tetlock, A., Yost, C.K., Stavrinides, J., and R.G. Manzon. 2012. Changes in the gut microbiome of the sea lamprey during metamorphosis. Applied Environmental Microbiology 78 (21):7638-7644.

Timoshevskiy, V.A., Timoshevskaya, N.Y., and Smith, J.J. 2019. Germline-specific repetitive elements in programmatically eliminated chromosomes of the sea lamprey (Petromyzon marinus). Genes (Basel) 10 (10).

Tulenko, F.J., McCauley, D.J., Mackenzie, E.L., et al. 2013. Body wall development in lamprey and a new perspective on the origin of vertebrate paired fins. Proceedings of the National Academy of Sciences of the United States of America 110 (29):11899-11904.

Yamazaki, Y., Yokoyama, R., Nagai, T., and A. Goto. 2011. Formation of a fluvial non-parasitic population of Lethenteron camtschaticum as the first step in petromyzontid speciation. Journal of Fish Biol 79 (7):2043-2059.

Zhu, M., Yu, X., Ahlberg, P.E., et al. 2013. A Silurian placoderm with osteichthyan-like marginal jaw bones. Nature 502 (7470): 188-193. 